\title{
Acquired Cytomegaloviral Infection
}

National Cancer Institute

\section{Source}

National Cancer Institute. Acquired Cytomegaloviral Infection. NCI Thesaurus. Code C122426.

An infection with the Cytomegalovirus that is not present from birth. 